Discourse and Communication for Sustainable Education, vol. 7, no. 2, pp. 118-131, 2016

\title{
How Sustainable is Pupil Self-Esteem as an Educational Objective for Religious Minorities?
}

\author{
Phra Nicholas Thanissaro \\ The University of Warwick, the United Kingdom
}

\begin{abstract}
Although the importance of self-esteem in educational achievement is contested, it remains a significant touchstone of multicultural religious education. This study set out to establish differences in demographics and attitudes between high self-esteem and low self-esteem Buddhist teenagers who are a small religious minority in Britain. Low self-esteem teens expressed less well-being, more worry in relationships with their family and friends, low motivation in school, more supernatural beliefs, more introversion, felt Buddhism irrelevant and used the internet more. Self-esteem was not linked to religious values or environmental concern. Narrow focus on self-esteem as an educational aim risks the known weaknesses of multiculturalism that have since been overcome in pluralist education. The limited usefulness of the self-esteem concept does however reveal ways forward for teachers of minority education, introverts and sustainability.
\end{abstract}

Keywords: self-esteem, Buddhism, teenagers, psychological type, sustainability.

\section{Introduction}

When education is referred to as 'sustainable' rather than 'for sustainability', there is an expectation that it should give deeper attention to the process of education itself (Sterling, 2008, 63) and importance to the qualities of the learner - valuing, sustaining and realizing human potential and social wellbeing (Sterling, 2001, 22). Where consideration is given to the way people interact with their ecology, sustainable education must of necessity involve personality factors such as attitudes, awareness and feelings of responsibility (Chansomsak \& Vale, 2008, 37). Such educational objectives leave teachers with the challenge of finding the sort of affirmation and empowerment to correspond with the objectives of sustainability - questions of implementation ultimately rooted in the sort of self-image the teacher desires to see in the pupil.

Self-esteem has been defined as an individual's sense of self-worth, or the extent to which a person values, approves of, appreciates, prizes or likes him or herself (Blascovitch \& Tomaka, 1991) and has been related to many psychological domains including personality, behaviour, socioeconomic factors, health and clinical psychology. Self-esteem is a widely used construct both in popular and formal psychology (Baumeister et al., 
2003; Lipnevich, 2006). Self-esteem is acknowledged for its role in allowing adolescents to cope and adjust to their situation (Coleman \& Hendry, 1999, 56). The earliest research considered low self-esteem to be related to depression, anxiety and poor school performance (Rosenberg, 1965). More recent research on self-esteem has come to understand that, like self-concept, it is best construed as multi-dimensional - i.e. a young person may feel a stronger sense of self-worth in some situations than others.

In education, doubt has been cast over the reliability of links between the construct of self-esteem and school performance. Carl Roger's psychology of always praising and never criticising (Rogers, 1961) has been found to devalue praise and confuse young people, contributing to narcissism and other forms of inflated self-esteem (Geller, 1982). Incongruously, research has shown high self-esteem is partly the result of good school performance. Efforts to boost the self-esteem of pupils have not been shown to improve academic performance and have sometimes proved counterproductive. The rest of the observable correlation may be attributable to the 'Pygmalion Effect' whereby the greater the expectation placed upon pupils, the better they perform (Rosenthal \& Jacobson, 1968). Nonetheless, high self-esteem has been shown to be linked to persevering longer in the face of failure and resilience against stress and trauma. Children without any friends tended to have low self-esteem, but lack of friends may be result rather than the cause of having low self-esteem (Bishop \& Inderbitzen, 1995). Low self-esteem has been shown to increase delinquency in affluent groups but boosted self-esteem resulted from delinquency in low socio-economic groups. Nonetheless, statistical links seem to exist between high self-esteem and happiness (Baumeister et al., 2003, 28) and between low self-esteem and eating disorders.

In spite of the mixed reception for the self-esteem construct in the general education literature, in multicultural education it remains one touchstone of educational outcomes to the extent that Tiedt and Tiedt $(1986,23)$ claimed:

A major goal for educators ... is to help children develop positive self-concepts, to view themselves as worthwhile persons, and to perform accordingly ... this emphasis is especially crucial for children from minority groups.

Moreover, low self-esteem identifiers of marginalization or embarrassment can occur where there is no acknowledgment in school of a pupil's cultural background (Nesbitt, 2004, 144).

The present study breaks new ground in moving away from consideration of selfesteem in the dominant culture of a society (e.g. Christians in a broadly Christian culture) to study self-esteem in Buddhists who form a tiny minority $(0.4 \%)$ of the UK demographic. The rationale for this study was to find whether self-esteem is linked with particular attitudes or individual differences which overlap with those of sustainable education and to suggest ways to build aspects of self-esteem into education appropriate to Buddhists and sustainable education - concluding the likely effectiveness of the 'uniqueness' construct for minorities, if education is to be made truly inclusive. 


\section{Methodology}

\section{Sample}

At the time of the 2011 census, there were 247,743 Buddhists in England and Wales, 22,715 of whom were teenagers. A survey was completed by a convenience sample of 417 self-identifying Buddhist teens attending temples in Britain or displaying an interest in Buddhist keywords ${ }^{1}$ on their Facebook page. The sample consisted of 225 male $(54 \%)$ and 192 females $(46 \%)$ aged between 13 and $20(M=16.33, \mathrm{SD}=2.34)$ and included Buddhists of Asian (52\%), White (34\%), Mixed (11\%), Chinese (2\%) and Black (1\%) ethnicity. Some of these Buddhists had ethnic roots in the countries of Asia (so-called 'heritage' Buddhists) while others had converted to Buddhism independent of their family's influence (so-called 'convert' Buddhists). The two sorts of Buddhists have styles of religious practice often as different from each other as they are from non-Buddhist religions - and therefore warrant separate examination. In this research, heritagestyle Buddhists have been operationalized as including those who have self-identified as Asian-Indian, Asian-Pakistani, Asian-Bangladeshi, Any Other Asian and Chinese. Convert-style Buddhists have been operationalized as including Black-African, Black-Caribbean and White. In this sample, of those for whom religious style could be ascertained, ${ }^{2}$ $61 \%$ were heritage and $39 \%$ were convert.

\section{Instrument}

A compound survey with design details similar to that described by Thanissaro (2016), collected demographic data such as parental employment, social class, internet use, psychological type, neuroticism, sex, religious affiliation, age and ethnicity (hereafter collectively referred to as 'individual differences') and mapped attitudes. The survey questions central to this particular article was a section that measured self-esteem. Although there are several possible ways to assess self-esteem (Heatherton \& Wyland, 2003), the Coopersmith measure was adopted since it is one of the self-esteem scales proven to perform best on factor analysis (Demo, 1985). The school short-form of the Self-Esteem Inventory [SEI] used in this study was developed to provide an alternative to the full 50-item SEI (Coopersmith, 1967; 1981) when time for completion is limited (see Hills et al., 2011). Devised for use specifically with children, the instrument assesses selfesteem in the contexts of school, parents and peers. The short-form school SEI consists of the 25 -items with self-esteem scores calculated from the aggregate item scores with higher scores indicating greater self-esteem. Questions on the SEI relate to global self-

\footnotetext{
${ }^{1}$ The keywords included the words: arhat (Buddhism), Buddhism, Buddhism Theravada, Buddhist, Buddhist meditation, Burmese Buddhist temple, Dhammakaya meditation, Dhammakaya movement, Foundation for the Preservation of the Mahayana Tradition, FWBO, Gautama Buddha, interbeing, Karma Kagyu, Mahayana, merit (Buddhism), New Kadampa Tradition, Order of Interbeing, Samatha, Soka Gakkai International SGI, Theravada, Theravada Buddhism, Theravada Buddhist, Tibetan Buddhism, Triratna Buddhist Community, Vietnamese Family of Buddhism, Vipassana, Vipassana meditation, Zen, Thich Nhat Hanh, Buddhism in Bangladesh, Buddhahood, Diamond Way Buddhism, Buddha's Dharma, Pure Land Buddhism, Buddha's Light International Association.

${ }^{2}$ Not possible where ethnicity was 'mixed'.
} 
esteem, relations with parents and relationships with answers on a yes/no scale. Scores can theoretically range from a minimum score of zero to a maximum of 25 . Zhang (1997) reported the internal reliability and construct validity of the school short-form SEI to be satisfactory. Previous research has employed the school short-form SEI in relation to physical activity (Delaney \& Lee, 1995), effectiveness of counselling (Sapp, 1994) and medical health (Stark et al., 1990). In aspects of Christian religiosity, selfesteem using this measure has been related to God image (Francis, 2005; Robbins et al., 2007), frequency of prayer (Francis \& Gibbs, 1996), religious behaviour and personality (Hills et al., 2006), religiosity (Jones \& Francis, 1996) and religious rejection (Williams et al., 2006).

\section{Procedure}

Surveys were distributed in the period 2013-14 and were completed in the participants' own time and for those unable to complete the survey immediately, a stamped addressed envelope was provided to facilitate return. For the online part of the survey a Qualtrics web-based survey software was hosted on the St Mary's Centre website. ${ }^{3}$ Teenagers were directed to this survey by clicking sidebar advertising banners that appeared on their Facebook page if they belonged to a Buddhist interest group. The online sample was limited to those both resident in the UK and falling within the target age-range.

Participants were divided into two roughly equal groups - the 'High SEI' group who had above-average SEI scores and the 'Low SEI' group who had below-average scores. In practice, the mean SEI score for the Buddhist teenagers in this study was 15.667. Also, although the attitude questions in the survey used a five-point Likert scale, for ease of analysis the 'agree strongly' and 'agree' responses were recoded into one category styled 'agree'. This has been compared statistically with a non-agree category consisting of scores for the remainder of responses from the 'disagree strongly', 'disagree' and 'not certain' categories. SPSS syntax was also used to calculate psychological type and SEI score. The resulting dataset was analyzed by means of the Chi-square ${ }^{4}$ cross-tabulation routines of the SPSS statistical package (SPSS Inc., 1988) for categorical variable data such as levels of attitude question agreement or the independent samples $t$-test routine for continuous variable data such as SEI scores.

\section{Findings}

Findings have been divided into two subsections. In the first part, self-esteem is compared with individual differences that include demographics and personality type. In the second part, links are explored between self-esteem and difference in agreement with attitude statements concerning well-being, family, school, friends and relationships, supernatural belief and Buddhism, for which significant differences were found between the high and low self-esteem groups.

\footnotetext{
${ }^{3}$ www.st-marys-centre.org.uk

${ }^{4}$ Or the equivalent $I$ for SSRT comparison of psychological type ratios.
} 


\section{Part 1: Individual Differences}

Table 1

Summary of the Relation of Individual Differences to Self-esteem

\begin{tabular}{|c|c|c|}
\hline \multicolumn{2}{|l|}{ Linked with } & \multirow{2}{*}{ No link } \\
\hline High Self-Esteem & Low Self-Esteem & \\
\hline Parents in full-time employment & Emotionality & Buddhist affiliation \\
\hline Higher social class & Instability & Age \\
\hline Less than 2 hours of internet use per day & Being female & Religious style \\
\hline Extraversion & & Temple attendance \\
\hline Being a proper Buddhist & & Meditation frequency \\
\hline Being a religious person & & Scripture reading \\
\hline & & Bowing to parents \\
\hline
\end{tabular}

As shown in Table 1, the Buddhist teenagers' responses to general demographic questions, some significant differences were found between high and low self-esteem participants. Significantly more high self-esteem teens had a parent in full-time employment $^{5}$ rather than in part-time work, unemployed or retired. Significantly more high self-esteem teens did not belonged to 'working class' families. ${ }^{6}$ Additionally, $72 \%$ of high self-esteem teens used the internet for no more than 2 hours per day. ${ }^{7}$ In terms of psychological type, a significantly higher proportion of high self-esteem teens had an extravert orientation $(62 \%) .{ }^{8}$ Also almost twice as many high self-esteem teens had a for Dominant Feeling [Dt.F] preference. ${ }^{9}$ High self-esteem teens were also scored significantly less neurotic in terms of emotionality and stability. ${ }^{10} \mathrm{~A}$ comparison was made between Buddhist adolescents and a large sample of religiously-undifferentiated adolescents (RUA) from Year 9 and Year 10 pupils from Cornwall that used the same instrument and age-range (Hills et al., 2011). Buddhist adolescents as a whole were not significantly different in their self-esteem score from RUA ${ }^{11}$ - therefore being a religious minority, in itself, is not synonymous with low self-esteem. No heightened degree of participation in Buddhist practice, whether it be meditation, ${ }^{12}$ temple attendance, ${ }^{13}$ or scripture reading ${ }^{14}$ was found to have any significant link with self-esteem. Male Buddhist teens did however display a significantly higher self-esteem score than the females ${ }^{15}$ - but this

\footnotetext{
${ }^{5}$ Father $79 \%\left[\chi^{2}=9.33 \mathrm{p}<.01\right] /$ mother $55 \%\left[\chi^{2}=10.99 \mathrm{p}<.01\right]$.

${ }^{6}$ By definition where the family breadwinner was employed in a manual labour: father $86 \%$ $\left[\chi^{2}=13.45 \mathrm{p}<.01\right] /$ mother $57 \%\left[\chi^{2}=20.22 \mathrm{p}<.001\right]$.

${ }^{7}$ Which is significantly lower usage than for low self-esteem teens $\left[\chi^{2}=7.95 \mathrm{p}<.01\right]$.

${ }^{8}$ By comparison only $37 \%$ of low self-esteem teens were extravert which was significantly lower $\left[\chi^{2}=14.15 \mathrm{p}<.001\right]$. In general extraverts form only $52.3 \%$ of the normative UK type distribution (Kendall and McHenry 1998).

${ }^{9} 29 \%$ as compared with only $17 \%$ in low self-esteem teens $[I=0.59 \mathrm{p}<.05]$.

$1090 \%$ of high self-esteem teens were significantly less emotional $\left[\chi^{2}=45.07 \mathrm{p}<.001\right]$ and $79 \%$ were more stable $\left[\chi^{2}=44.07 \mathrm{p}<.001\right]$ than low self-esteem teens.

${ }^{11} M_{\text {budd }}=15.05$, S.D. $=5.49 ; M_{\text {rua }}=15.03$, S.D. $=5.33, t[3201]=0.02$, NS.

${ }^{12} M_{\text {meditation }+}=15.30$, S.D. $=5.29 ; M_{\text {meditation }-}=15.42$, S.D. $=5.30, t[330]=-0.18$, NS.

${ }^{13} M_{\text {templet }}=15.15$, S.D. $=5.39 ; M_{\text {temple }}=15.56$, S.D. $=5.16, t[330]=-0.70, \mathrm{NS}$.

${ }^{14} M_{\text {scripturet }}=15.20$, S.D. $=5.52 ; M_{\text {scripture }}=15.46$, S.D. $=5.11, t[329]=-0.44$, NS.

${ }^{15} M_{\text {male }}=16.13$, S.D. $=5.22 ; M_{\text {female }}=14.30$, S.D. $=5.21, t[330]=3.18, \mathrm{p}<.01$.
} 
difference is to be expected in all measures of self-esteem and was also shown to be the case in the religiously undifferentiated comparison sample. Buddhists in their early teens were not significantly different in their self-esteem score than those in their late teens. ${ }^{16}$ Heritage Buddhist teens were not significantly different in their self-esteem score than convert Buddhist teens, ${ }^{17}$ and degree of affective Buddhist religiosity as measured by TSAB-R did not correlate significantly with self-esteem. ${ }^{18}$

\section{Part 2: Attitudes Statistically Linked with Self-Esteem}

For clarity, in the remainder of findings subsections, significant differences in response to attitude question items between high and low self-esteem teens will be displayed as tables.

\section{Well-being}

Table 2

Degree of Agreement on Well-Being Statements for Low and High Self-Esteem Teens

\begin{tabular}{lccccc}
\hline & \multicolumn{2}{c}{$\%$ agree for } & \multirow{2}{*}{$\chi^{2}$} & p $<$ \\
\cline { 2 - 4 } & Low SEI & High SEI & & \\
\hline I have sometimes considered taking my own life & 40 & 13 & 16.0 & .001 \\
\hline I feel I am not worth much as a person & 20 & 6 & 8.8 & .01 \\
\hline I would not describe myself as happy & 25 & 6 & 13.4 & .001 \\
\hline I often feel depressed & 53 & 11 & 35.8 & .001 \\
\hline $\begin{array}{l}\text { There is nothing I can do to help solve the world's } \\
\text { problems }\end{array}$ & 14 & 7 & 4.5 & .05 \\
\hline $\begin{array}{l}\text { I am concerned about the risk of pollution to the envi- } \\
\text { ronment }\end{array}$ & 78 & 78 & 0.0 & NS \\
\hline I am a unique individual & 71 & 87 & 6.5 & .05 \\
\hline I feel my life has a sense of purpose & 71 & 89 & 8.9 & .01 \\
\hline I find life really worth living & 75 & 88 & 5.0 & .05 \\
\hline $\begin{array}{l}\text { The wellbeing of my fellow students/workers is impor- } \\
\text { tant to me }\end{array}$
\end{tabular}

As shown in Table 2, for well-being-related statements, as might be expected, those of lower self-esteem were significantly more likely to consider taking their own life, feel worthless as a person, unhappy, depressed and powerless in the face of the world's problems. Self-esteem was not significantly linked however with concern for the environment. Those of higher self-esteem were significantly more likely to see themselves as a unique individual, with a sense of purpose in life and find life worth living. Those of high self-esteem were significantly more likely to lend importance to the wellbeing of their fellow students or workers.

\footnotetext{
${ }^{16} M_{\text {early }}=14.91$, S.D. $=5.37 ; M_{\text {late }}=15.93$, S.D. $=5.12, t[330]=-1.74$, NS.

${ }^{17} M_{b b t}=15.53$, S.D. $=5.17 ; M_{c b t}=15.13$, S.D. $=5.41, t[292]=0.60$, NS.

${ }^{18}$ Pearson $r[330]=0.19$, NS.
} 


\section{Family}

Table 3

Degree of Agreement on Family Statements for Low and High Self-Esteem Teens

\begin{tabular}{lccccc}
\hline & \multicolumn{2}{c}{$\%$ agree for } & \multirow{2}{*}{$\chi^{2}$} & \multirow{2}{*}{ p } \\
\cline { 2 - 4 } & Low SEI & High SEI & & \\
\hline My family disapproves of what I do with my spare time & 46 & 26 & 7.1 & .01 \\
\hline Adults do not listen to young people & 51 & 32 & 6.3 & .05 \\
\hline Adults do not respect young people & 37 & 23 & 4.2 & .05 \\
\hline I find it helpful to talk about my problems with my mum & 54 & 75 & 8.0 & .01 \\
\hline I find it helpful to talk about my problems with my dad & 41 & 63 & 8.2 & .01 \\
\hline I get on well with my family & 72 & 90 & 9.2 & .01 \\
\hline My family are supportive of me & 88 & 98 & 6.6 & .05 \\
\hline
\end{tabular}

As shown in Table 3, in their family life, those of low self-esteem were significantly more likely to feel their family disapproved of what they did in their spare time and felt they were not listened to or respected by adults. Those of higher self-esteem were significantly more likely to find it helpful to talk about their problems with their parents, get on well with their family and find their family supportive.

\section{School}

Table 4

Degree of Agreement on School Statements For Low and High Self-Esteem Teens

\begin{tabular}{|c|c|c|c|c|}
\hline & \multicolumn{2}{|c|}{$\%$ agree for } & \multirow{2}{*}{$\chi^{2}$} & \multirow{2}{*}{$\mathrm{p}<$} \\
\hline & Low SEI & High SEI & & \\
\hline I am worried about my exams at school & 83 & 60 & 10.9 & .01 \\
\hline I often worry about my school work & 69 & 50 & 5.9 & .05 \\
\hline School is boring & 30 & 11 & 9.9 & .01 \\
\hline I am happy in my school & 71 & 90 & 10.2 & .01 \\
\hline I like the people I go to school with & 72 & 92 & 12.2 & .001 \\
\hline My school is helping me prepare for life & 70 & 84 & 4.6 & .05 \\
\hline
\end{tabular}

As shown in Table 4, for attitudes concerning school, those of low self-esteem were significantly more likely to worry about exams and schoolwork and find school boring. At school, those of higher self-esteem were significantly more likely to be happy, like the people they went to school with and feel school was preparing them for life.

\section{Friends and Relationships}

As shown in Table 5, for friendship-related statements, those of low self-esteem were significantly more likely to feel pressurized by friends to do things they didn't want to do and were more likely to (restrict themselves to) have exclusively Buddhist friends. Those of high self-esteem were significantly more likely to find it helpful to talk about their problems with their friends and want to live close to them. As shown in relationships, those of low self-esteem were significantly more likely to worry about how they got on with others, about their sex-life and their attractiveness to the opposite sex. 
Table 5

Degree of Agreement on Friends and Relationships Statements for Low and High SelfEsteem Teens

\begin{tabular}{lccccc}
\hline & \multicolumn{2}{c}{$\%$ agree for } & \multirow{2}{*}{$\chi^{2}$} & $\mathrm{p}<$ \\
\cline { 2 - 3 } & Low SEI & High SEI & & & \\
\hline $\begin{array}{l}\text { Sometimes I feel pressured by my friends to do things } \\
\text { I don't want to do }\end{array}$ & 35 & 21 & 4.3 & .05 \\
\hline Most of my friends are Buddhist & 28 & 12 & 6.7 & .01 \\
\hline $\begin{array}{l}\text { I find it helpful to talk about my problems with my } \\
\text { friends }\end{array}$ & 64 & 82 & 7.7 & .01 \\
\hline I like to live close to my close friends & 54 & 74 & 7.1 & .01 \\
\hline I am worried about how I get on with other people & 51 & 24 & 13.0 & .001 \\
\hline I am worried about my sex life & 17 & 6 & 5.8 & .05 \\
\hline I am worried about my attractiveness to the opposite sex & 46 & 28 & 6.3 & .05 \\
\hline
\end{tabular}

\section{Supernatural Belief}

Table 6

Degree of Agreement on Statements Related to Supernatural Beliefs for Low and High Self-Esteem Teens

\begin{tabular}{lccccc}
\hline & \multicolumn{2}{c}{$\%$ agree for } & \multirow{2}{*}{$\chi^{2}$} & \multirow{2}{*}{$\mathrm{p}<$} \\
\cline { 2 - 5 } & Low SEI & High SEI & & \\
\hline I believe in the Devil (Mara) & 36 & 18 & 7.7 & .01 \\
\hline I believe in ghosts & 57 & 26 & 16.4 & .001 \\
\hline I believe it is possible to contact the spirits of the dead & 36 & 18 & 7.7 & .01 \\
\hline I believe in angels & 45 & 20 & 12.4 & .001 \\
\hline I believe in black magic & 19 & 7 & 6.3 & .05 \\
\hline I am frightened of going into a church alone & 28 & 7 & 13.9 & .001 \\
\hline I am frightened of going into a temple alone & 28 & 7 & 13.9 & .001 \\
\hline
\end{tabular}

As shown in Table 6, in terms of supernatural belief, low self-esteem teens were significantly more likely to believe in the devil, ghosts, the possibility of contacting spirits of the dead, angels, black magic and be frightened to go into a church or temple alone.

\section{Buddhism}

Table 7

Degree of Agreement on Buddhist Statements for Low and High Self-Esteem Teens

\begin{tabular}{lccccc}
\hline & \multicolumn{2}{c}{$\%$ agree for } & \multirow{2}{*}{$\chi^{2}$} & p $<$ \\
\cline { 2 - 4 } & Low SEI & High SEI & & \\
\hline Buddhist teachings seem irrelevant to life today & 23 & 11 & & 4.4 & .05 \\
\hline The temple community seems irrelevant to life today & 19 & 9 & 4.0 & .05 \\
\hline I consider myself a proper Buddhist & 37 & 58 & 7.6 & .01 \\
\hline I am a religious person & 47 & 66 & 6.4 & .05 \\
\hline
\end{tabular}


As shown in Table 7, for Buddhist attitudes, those of low self-esteem were significantly more likely to find Buddhist teachings and the temple community irrelevant. Those of higher self-esteem, by contrast, were significantly more likely to consider themselves a proper Buddhist and a religious person.

\section{Discussion}

\section{Individual Differences and Attitudes Linked with High Self-Esteem}

This study found that high self-esteem teens were found to express significantly more sense of well-being, had more positive engagement with their family and friends, were happier and more purposeful at school and felt more genuinely Buddhist. Consistent with the finding of Francis and Jones (1996) among 16 year olds, it was found that higher levels of self-esteem were linked with higher classes of socio-economic group perhaps not surprisingly, since young people in these socio-economic groups probably have greater opportunities in their lives. Similarly, those of higher self-esteem had significantly higher levels of extraversion and parental employment, but lower rates of internet use.

\section{Individual Differences and Attitudes Linked with Low Self-Esteem}

By contrast, low self-esteem teens expressed significantly less sense of well-being, were more worried in relationships, had less positive engagement with their family, were worried and under-motivated in school and felt pressurized in friendships, held more supernatural beliefs, felt Buddhism irrelevant and used the internet more. Female Buddhist teens scored significantly lower in terms of self-esteem than male Buddhist teens - but no more so than has been documented for males and females of undifferentiated religion. Those of lower self-esteem had significantly higher levels of introversion and more instability and emotionality. It is likely that those of low self-esteem associated mainly with their in-group mainly because introverts find it easier to 'open-up' to those they are familiar with.

\section{Individual Differences and Attitudes Independent of Self-Esteem}

Age and religious style, Buddhist affiliation, temple attendance, meditation frequency, scripture reading, bowing to parents and concern for the environment did not prove to be factors where self-esteem was statistically linked - echoing the findings of Francis and Gibbs (1996) for Christian children. Maltby and colleagues (1999) did however find, that high self-esteem was associated with personal prayer and negatively related to extrinsic forms of religion and church attendance. It is encouraging that those of this religious minority seemed to be on an equal self-esteem footing with other children in school - as this commends the effectiveness of the British system of pluralist education. 


\section{Sustainability and Localized Education Objectives}

The sustainability of education can be related to the appropriateness with which educational objectives are aligned with local culture. Hoffman (1996) recommended reform in education concerning teaching and learning about culture, pedagogy and critical perspectives, since self-esteem is not as highly regarded in all cultures. Sustainable education needs to understand localized concepts of self and relationship to allow these to be leveraged to sustainable ends. Accordingly, the limitations of self-esteem for sustainable education, especially for cultural-religious minorities and introverts is elaborated below with suggestions for compensatory interventions by teachers.

\section{Self-Esteem and Cultural-Religious Minorities}

It is obvious from the findings of this study, that even though Buddhists are a tiny religious minority in Britain, their self-esteem is not significantly different from peers in the mainstream population - so being a minority doesn't automatically predict low selfesteem. Self-esteem seemed to be related to religious affiliation rather than aspects of religious participation, since degree of religious participation, whether measured in terms of temple attendance, frequency of meditation, scripture reading or bowing to parents in respect, had no significant link with self-esteem. Self-esteem might therefore be considered the sign of a boundary marker or a sense of 'uniqueness'. Such in-group pride is a double-edged sword often encouraging sectarianism at the expense of acceptance of difference or holistic education initiatives in general (Badjanova \& Iliško, 2015, 134). Furthermore, cultural and ethnic minority groups may have their own paradigms for viewing self and may not be swayed by any multicultural educator's emphasis on how good it feels to be unique. This understanding of the limitations of self-esteem lies at the heart of the distinction between 'pluralist' rather than 'multicultural' education where pluralism implies knowing one's own identity while having a respectful awareness of others (e.g. de Souza, 2016, 134), rather than the multiculturalist approach of each ingroup being merely proud of its own identity. Emphasis on 'responsibility' and awareness of one's identity in relation to that of others, rather than pride in personal uniqueness would be a more sustainable touchstone of pluralist education.

\section{Self-Esteem and Pupil Psychological Type}

Self-esteem may be a construct that tells us more about extraversion than about subjective quality of life. Many aspects of extraversion are also reflected in aspects of high-self esteem behaviour whether it be talking about problems with parents or friends, relevance of religious community or liking the people they go to school with. To put too much emphasis on self-esteem would be to ignore the plight of introverts in education. Following the Jungian rather than the Eysenckian interpretation, being extravert is not superior to being introvert - simply a different manner of being. Thus although low self-esteem might be considered problematic, it should not be confounded with introverted Psychological Type. Education has a role to encourage socialization and collectivism, but teachers must consider the extent to which introverts need to be encouraged to change. The introvert risk of isolation and dwelling in an inner world of supernatural beliefs should stimulate teachers to provide avenues of creative expression through 
writing or drama to allow those pupils to become aware of their own worldview - and this way make the school experience meaningful to the full range of psychological types. The school system generally does not facilitate introvert approaches to study, but if teachers are aware of the jarring experience introverts have of school, models can be provided of introvert way of 'doing' leadership (Cain, 2012), such as appreciating pupil self-reliance. Educational activities can be designed to give a balance of activities such as time for silence in schools, which encourages an amenable input by introverts, with correspondingly less emphasis on discussion, group activities and verbal expression (Lees, 2012). Such a shift would help boost well-being of introverts and make school experience more meaningful. Rather than forcing introvert pupils to be something they are not, they can be encouraged to 'wear' their introversion more comfortably. If raising self-esteem of pupils is to remain one of the main educational objectives, ways to boost success for introvert teens should mean more opportunity for quiet reflection, which would improve academic performance of low-esteem introvert teens, thereby indirectly boosting their self-esteem.

\section{Self-Esteem and Sustainability}

At a time when more than ever, a younger generation needs to become aware of the collective responsibility for the planet, rampant individualism cannot be considered sustainable. Where child-centred education emphasizes self-esteem, particularly inflated self-esteem, it is one reason why formal education remains part of the problem of unsustainability rather than a solution (Sterling, 2008, 64). At the same time, this study concurs with the recommendation of Chansomsak and Vale $(2008,46)$ that Nature should not be exploited for establishing a self-image based on wealth. The solution to the problem lies, for the most part, in reinventing self-image to something more sustainable. If pupils can be trained, instead of basking in self-esteem, to expand their concerns to include others, their self-interested behaviours will be changed to actions in the interest of all.

\section{Conclusion}

Although the main aim of the Buddhist approach to education is not to promote sustainability, Buddhists certainly focus on relationships. Self-esteem, especially inflated self-esteem however, is not thought a desirable end-product of nurture in Buddhism, ${ }^{19}$ where humility, sensitivity to aspects of personal suffering and collectivist values are still strongly encouraged. The problem with self-esteem is the way in which it encourages boundary demarcation that compromises the closeness of relationship between self and other. Since almost all social and ecological problems are caused by dysfunctional relationships between humans and the environment, looking beyond the self-esteem construct using localized knowledge such as that of the Buddhists, has much to offer the sustainable education discourse.

\footnotetext{
${ }^{19}$ Humility [nivāto] in the Buddhist Mangala Sutta [Kh.v.3, Sn.259-268] refers literally to the lack of inflated self-esteem.
} 


\section{Suggestions for Further Research}

Although this quantitative study has highlighted some of the limits of the selfesteem concept as a sustainable objective in education, it is not clear whether Buddhists are a special case, and it would be instructive to survey other religious minorities using the same methods. It would also be helpful to compare sustainable attitudes such as concern for the environment between schools putting more or less emphasis on selfesteem or extravert-orientated learning activities.

\section{References}

Badjanova, J. \& Iliško, D. (2015). Holistic approach as viewed by the basic school teachers in Latvia. Discourse and Communication for Sustainable Education, 6(1), 132-140. http://dx.doi.org/10.1515/dcse-2015-0010

Baumann, M. (2002). Paying homage to the Buddha in the West. In M. Baumann and C. S. Prebish (Eds.), Protective amulets and awareness techniques, or how to make sense of Buddhism in the West (pp. 52-63). London: University of California Press.

Baumeister, R. F., Campbell, J. D., Krueger, J. I. \& Vohs, K. D. (2003). Does high selfesteem cause better performance, interpersonal success, happiness, or healthier lifestyles? Psychological Science in the Public Interest, 4(1), 1-44. doi: 10.1111/ 1529-1006.01431

Bishop, J. A. \& Inderbitzen, H. M. (1995). Peer acceptance and friendship: An investigation of their relation to self-esteem. Journal of Early Adolescence, 15(4), 476489. doi: 10.1177/0272431695015004005

Blascovitch, J. \& Tomaka, J. (1991). Measures of self-esteem. In J. P. Robinson, P. R. Shaver and L. S. Wrightsman (Eds.), Measures of personality and social psychological attitudes (pp. 115-160). New York: Academic Press.

Cain, S. (2012). Quiet: The power of introverts in a world that can't stop talking. London: Penguin.

Chansomsak, S. \& Vale, B. (2008). The Buddhist approach to education: an alternative approach for sustainable education. Asia Pacific Journal of Education, 28(1), 3550. doi: 10.1080/02188790701850063

Coleman, J. C. \& Hendry, L. B. (1999). The Nature of adolescence. London: Routledge. Coopersmith, S. (1967). The antecedents of self-esteem. San Francisco, CA: Freeman. Coopersmith, S. (1981). Self-esteem inventories. Palo Alto, CA: Consulting Psychologists Press Inc.

de Souza, M. (2016). The spiritual dimension of education - addressing issues of identity and belonging. Discourse and Communication for Sustainable Education, 7(1), 125-138. Retrieved from: http://dx.doi.org/10.1515/dcse-2016-0009

Delaney, W. \& Lee, C. (1995). Self-esteem and sex roles among male and female high school students: their relationship to physical activity. Australian Psychologist, 30(2), 84-87. doi: 10.1080/00050069508258908

Demo, D. H. (1985). The measurement of self-esteem: Refining our methods. Journal of Personality and Social Psychology, 48(6), 1490-1502. doi: 10.1037/00223514.48.6.1490

Francis, L. J. (2005). God Images and Self-esteem: a study among 11-18 year-olds. Research in the Social Scientific Study of Religion, 16, 105-122. 
Francis, L. J. \& Gibbs, D. (1996). Prayer and self-esteem among 8- to 11-year-olds in the United Kingdom. Journal of Social Psychology, 136(6), 791-793. doi: 10.1080/ 00224545.1996 .9712256

Francis, L. J. \& Jones, S. H. (1996). Social class and self-esteem. The Journal of Social Psychology, 136(3), 405-406. doi: 10.1080/00224545.1996.9714019

Geller, L. (1982). The failure of self-actualization theory: a critique of Carl Rogers and Abraham Maslow. Journal of Humanistic Psychology, 22(2), 56-73. doi: 10.1177/ 0022167882222004

Heatherton, T. F. \& Wyland, C. L. (2003). Assessing Self-Esteem. In S. J. Lopez \& C. R. Synder (Eds.), Positive psychology assessment: A handbook of models and measures (pp. 219-233). Washington, DC: American Psychological Association.

Hills, P. R., Francis, L. J. \& Jennings, P. (2006). Religious behaviour, personality and dimensions of self-esteem among 13- to 15-year-old adolescents. Journal of Research on Christian Education, 15(1), 61-76.

Hills, P. R., Francis, L. J. \& Jennings, P. (2011). The school short-form Coopersmith Self-Esteem Inventory: Revised and Improved. Canadian Journal of School Psychology, 26(1), 62-71. doi: 10.1177/0829573510397127

Hoffman, D. M. (1996). Culture and self in multicultural education: Reflection on discourse, text, and practice. American Educational Research Journal, 33(3), 545569. doi: 10.3102/00028312033003545

Jones, S. H. \& Francis, L. J. (1996). Religiosity and self-esteem during childhood and adolescence. In L. J. Francis, W. K. Kay and W. S. Campbell (Eds.), Research in Religious Education (pp. 189-206). Leominster: Gracewing.

Kendall, B. \& McHenry, R. (1998). Technical supplement to the MBTI® Manual. Oxford: Oxford Psychologists Press.

Lees, H. E. (2012). Silence in schools. Stoke-on-Trent: Trentham Books.

Lipnevich, A. A. (2006). Low self-esteem: myth or reality? Focus on Basics, 8(B), 1-7. Retrieved April 1, 2016, from: http://www.ncsall.net/index.html@id=1105.html

Maltby, J., Lewis, C. A. \& Day, L. (1999). Religious orientation and psychological well-being: The role of the frequency of personal prayer. British Journal of Health Psychology, 4(4), 363-378. doi: 10.1348/135910799168704

Nattier, J. (1995). Visible \& invisible: The politics of representation in Buddhist America. Tricycle, The Buddhist Review, 5(1), 42-49.

Nesbitt, E. (2004). Intercultural education: Ethnographic and religious approaches. Brighton: Sussex Academic Press.

Numrich, P. D. (1996). Old wisdom in the new world: Americanization in two immigrant theravada Buddhist temples. Knoxville: University of Tennessee Press.

Robbins, M., Francis, L. J. \& Kerr, S. (2007). God images and self-esteem among secondary school pupils in South Africa. In P. Hegy (Ed.), What do we imagine God to be? The function of 'God images' in our lives (pp. 89-107). Lampeter: Edwin Mellen Press.

Rogers, C. R. (1961). On becoming a person: A therapist's view of psychotherapy. Boston, MA: Houghton Mifflin.

Rosenberg, M. (1965). Society and the adolescent self-image. Princeton, NJ: Princeton University Press.

Rosenthal, R. \& Jacobson, L. (1968). Pygmalion in the classroom. New York: Holt, Rinehart \& Winston. 
Sapp, M. (1994). Cognitive-behavioural counselling: Applications for African-American middle school students who are academically at-risk. Journal of Instructional Psychology, 21(2), 161-171.

SPSS Inc. (1988). SPSS User's Guide, 2nd Edition. New York: McGraw-Hill.

Stark, L. J., Spirito, A., Lewis, A. V. \& Hart, K. J. (1990). Encopresis: Behavioral parameters associated with children who fail medical management. Child Psychiatry and Human Development, 20(3), 169-179. 10.1007/BF00710186

Sterling, S. (2001). Sustainable education - re-visioning learning and change. Dartington: Schumacher Society Briefing No. 6, Green Books.

Sterling, S. (2008). Sustainable education - towards a deep learning response to unsustainability. Policy \& Practice: A Development Education Review, 6, 63-68. Retrieved September 1, 2016, from: http:/www.developmenteducationreview.com/issue6perspectives 1

Thanissaro, P. N. (2016). Temple-going teens: Religiosity and identity of Buddhists growing up in Britain. Unpublished PhD dissertation: University of Warwick.

Tiedt, P. L. \& Tiedt, I. M. (1986). Multicultural teaching: A handbook of activities, information, and resources. Boston: Allyn \& Bacon.

Williams, E., Francis, L. J. \& Robbins, M. (2006). Rejection of Christianity and selfesteem. North American Journal of Psychology, 8(1), 193-195.

Zhang, W. (1997). The self-esteem of junior high school students. Psychological Science (China), 20(6), 504-508. Retrieved October 10, 2016, from: http://en.cnki.com.cn/ Article_en/CJFDTOTAL-XLKX199706005.htm

\section{Acknowledgements}

A previous version of this article was presented at the University of Warwick's Centre for Education Studies Interdisciplinary Postgraduate Student Conference on 10 May 2014. The author would like to thank Revd. Canon Prof. Leslie J. Francis (University of Warwick) and Prof. Mandy Robbins (Glynduŵr University) for supervision of this research.

Correspondence concerning this paper should be addressed to Dr. Phra Nicholas Thanissaro is an Associate Fellow of Warwick Religions and Education Research Unit at the University of Warwick's Centre for Education Studies, Coventry CV4 7AL, UK, Email: p.thanissaro@warwick.ac.uk. 